\title{
Effects of MUL1 and PARKIN on the circadian clock, brain and behaviour in Drosophila Parkinson's disease models
}

\author{
Bartosz Doktór, Milena Damulewicz and Elżbieta Pyza*
}

\begin{abstract}
Background: Mutants which carry mutations in genes encoding mitochondrial ligases MUL1 and PARKIN are convenient Drosophila models of Parkinson's disease (PD). In several studies it has been shown that in Parkinson's disease sleep disturbance occurs, which may be the result of a disturbed circadian clock.

Results: We found that the ROS level was higher, while the anti-oxidant enzyme SOD1 level was lower in mul ${ }^{A 6}$ and park ${ }^{1}$ mutants than in the white mutant used as a control. Moreover, mutations of both ligases affected circadian rhythms and the clock. The expression of clock genes per, tim and clock and the level of PER protein were changed in the mutants. Moreover, expression of ATG5, an autophagy protein also involved in circadian rhythm regulation, was decreased in the brain and in PDF-immunoreactive large ventral lateral clock neurons. The observed changes in the molecular clock resulted in a longer period of locomotor activity rhythm, increased total activity and shorter sleep at night. Finally, the lack of both ligases led to decreased longevity and climbing ability of the flies.
\end{abstract}

Conclusions: All of the changes observed in the brains of these Drosophila models of PD, in which mitochondrial ligases MUL1 and PARKIN do not function, may explain the mechanisms of some neurological and behavioural symptoms of PD.

Keywords: Mitochondrial ligases, Clock genes, Clock neurons, ROS, SOD1, Autophagy, Locomotor activity rhythm, Sleep

\section{Introduction}

Mitochondria are important organelles in the metabolism of all cells, particularly in neurons because of their high energy demand [1]. As a result, several neurodegenerative diseases in which changes in mitochondrial structure and function lead to cell death [2]. One of these diseases is Parkinson's disease (PD), which can be caused by exposure to neurotoxins and/or by several gene mutations. These mutations include mutations in genes encoding PINK1, a mitochondrial kinase, and PARKIN, an E3 ubiquitin ligase, which leads to the autosomal recessive form of PD [3, 4]. These proteins regulate the function and morphology of mitochondria and

\footnotetext{
*Correspondence: elzbieta.pyza@uj.edu.pl

Department of Cell Biology and Imaging, Institute of Zoology

and Biomedical Research, Jagiellonian University, Kraków, Poland
}

promote mitophagy [5, 6]. Dysfunctional and damaged mitochondria lose their membrane potential, leading to activation and accumulation of PARKIN and degradation of the whole organelle $[7,8]$. In addition, there is another pathway that promotes mitophagy that acts in parallel to PINK1/PARKIN. This pathway involves mitochondrial ubiquitin ligase 1 (MUL1), which is responsible for mitochondrial integrity, fusion-fission processes, mitophagy and SUMOylation. Mutations in mul1 lead to typical PD symptoms, similar to those observed in pink1/park mutants [9]. In addition to molecular symptoms such as those observerd in mul1 and park mutants, Parkinson's disease are also characterized by other motor and nonmotor symptoms. Main motor disorders are bradykinesia and tremor, while non-motor disorders include pain, cognitive deficits, depression and sleep problems due to restless legs syndrome, REM sleep behaviour disorder (RBD) 
and excessive daytime sleepiness (EDS) or insomnia [10]. Sleep fragmentation and reduced sleep efficiency have an impact on patient quality of life and may accelerate the development of PD. Non-motor symptoms have also been observed in circadian rhythms of core body temperature and blood pressure. Because the circadian clock controls many of the abovementioned processes [11-13], the non-motor symptoms of PD might be a consequence of circadian clock malfunction and not a direct cause of the disease.

The Drosophila central clock (pacemaker) is composed of 150 neurons in the brain. These neurons are grouped into several clusters: large ventral lateral neurons (l-LNvs), small ventral lateral neurons (s-LNvs), lateral dorsal neurons (LNds), dorsal neurons (DN1-DN3) and posterior lateral neurons (LPNs) [14]. All l-LNvs and four of the five s-LNs are immunoreactive to pigmentdispersing factor (PDF), a main neurotransmitter of the clock. The molecular mechanism of the fruit fly clock is based on the cyclic expression of several clock genes and their proteins. The core clock genes include period (per), timeless (tim), clock (clk) and cycle (cyc) [15]. Per and tim expression is activated at the end of the day and at the beginning of the night by CLK/CYC transcription factors, acting as heterodimers. PER and TIM are synthesized at the end of the night, form heterodimers and, by entering the nucleus, inhibit the activity of CLK and CYC and the transcription of their own genes. This negative feedback loop is the main mechanism of the clock.

In the present study, we examined whether mutations of mull and park genes affect the molecular mechanism of the circadian clock and clock neurons, which may lead to changes in behavioural circadian rhythms and sleep disturbance. We studied whether both mutations affect cell protective mechanisms, synthesis of antioxidant proteins and autophagy. To evaluate the phenotypes associated with mull $^{A 6}$ and park $^{1}$ mutants, we also examined the longevity of the flies. We used Drosophila melanogaster since similar mechanisms and phenotypes of some human diseases have been described in this species $[5,6]$. In addition, Drosophila is a primary model used in neuroscience and the study of circadian rhythms and clocks.

\section{Materials and methods \\ Animals}

The following strains were used for the experiments: park $^{1}$ (null mutation of the park gene encoding the mitochondrial ligase PARKIN, Bloomington Drosophila Stock Centre) [16], mul1 $^{A 6}$ (null mutation of the mul1 gene encoding the mitochondrial ligase MUL1, kindly donated by Dr. Ming Guo, Brain Research Institute, USA) [9] and $w^{1118}$ (null mutation of the white gene encoding
ABC transporter, Bloomington Drosophila Stock Centre, which was used as controls because of the white genetic background of mutants mull $^{A 6}$ and park $^{1}$ ) [17]. Flies were maintained on standard yeast-cornmeal-agar medium at $25 \pm 1{ }^{\circ} \mathrm{C}$ under a day/night cycle, LD 12:12 (12 $\mathrm{h}$ of light and $12 \mathrm{~h}$ of darkness).

\section{Locomotor activity rhythm and sleep analyses}

One- to two-day-old males $(\mathrm{N}=32)$ were transferred to small glass tubes containing sugar-agar food medium. Vials were placed in DAMS monitors (Drosophila Activity Monitoring System, TriKinetics) and inside an incubator $\left(25^{\circ} \mathrm{C}\right)$. Monitors were equipped with infrared sensors that recorded the activity of the flies inside the vials every $5 \mathrm{~min}$. For the first 5 days, monitors were held in LD 12:12 conditions, followed by constant darkness (DD) for the next 6 days. The results from the second day of locomotor activity recording were analysed to estimate the total activity and duration of sleep during the day and during the night (Microsoft Excel plugin, BeFly kindly donated by Dr. E. Green, University of Leicester, [18] and Python 22 (http://www.python.org/). Sleep in flies was defined as the time in which they did not change their position for at least $5 \mathrm{~min}$. The experiment was repeated three times. In LD 12:12 and DD, the rhythm of locomotor activity was also examined, and the period of the circadian rhythm was estimated in DD.

\section{Whole-brain immunohistochemistry}

Seven-day-old males were fixed at ZT1 in 4\% paraformaldehyde in $0.2 \%$ PBT for $3 \mathrm{~h}$ at $4{ }^{\circ} \mathrm{C}$. Isolated brains were washed six times in PBS for 5 min each time. Next, they were incubated in 5\% normal goat serum (NGS) and 0.5\% bovine serum albumin (BSA) for $30 \mathrm{~min}$ at room temperature. Subsequently, brains were incubated overnight with a mouse primary antibody targeting PDF (1:1000, Developmental Studies Hybridoma Bank) or a rabbit antibody targeting ATG5, an autophagy protein (1:500, Abcam). Afterwards, brains were washed six times in $0.2 \%$ PBT for 5 min each time and incubated overnight at $4{ }^{\circ} \mathrm{C}$ with secondary goat anti-mouse Cy3-conjugated (1:500, Jackson ImmunoResearch) or goat anti-rabbit Alexa 488-conjugated (1:1000, MolecularProbes) antibodies, depending on the primary antibodies. Finally, brains were washed four times in $0.2 \%$ PBT and twice in PBS and mounted in Vectashield medium (Additional file 1: Table S1).

\section{Quantification of immunolabelling}

To measure the fluorescence intensity of ATG5 protein in the large ventral lateral neurons (l-LNvs), we used confocal microscopy. We identified cell bodies of l-LNvs using the anti-PDF antibody, and we scanned the same cell for 
labelling with the anti-ATG5 antibody. We selected all l-LNv cell bodies and measured the fluorescence intensity of the ATG5 protein. Images were collected with a Zeiss Meta 510 Laser Scanning Microscope (Additional file 2: Table S2).

\section{ROS measurements}

To measure whether ROS levels were increased in $m u l 1^{A 6}$ and park $^{1}$ mutants, 7-day-old males $(\mathrm{N}=10)$ of mutants and controls were decapitated at ZT0. Brains were isolated and washed twice in PBS for $10 \mathrm{~min}$. Next, the tissue was incubated with MitoSOX (ThermoFisher) for $10 \mathrm{~min}$ and mounted in Vectashield medium. Images were collected with a Zeiss Meta 510 Laser Scanning Microscope. The method has been described by Scialò et al. [19].

\section{Western blot}

Seven-day-old males $(\mathrm{N}=30)$ were frozen in liquid nitrogen at four time points (ZT1, ZT4, ZT13, ZT16) and decapitated. Heads were homogenized by sonication in $30 \mu \mathrm{l}$ of Laemmli buffer with a protease inhibitor (Boehringer, Mannheim), left for $30 \mathrm{~min}$ at $4{ }^{\circ} \mathrm{C}$ and frozen at $-20{ }^{\circ} \mathrm{C}$. Homogenates were centrifuged at $13,200 \mathrm{rpm}$ for $1 \mathrm{~h}$ at $4{ }^{\circ} \mathrm{C}$. Supernatants were collected and denatured at $85{ }^{\circ} \mathrm{C}$ for $5 \mathrm{~min}$. Total protein levels were measured using a Quant-iT Protein Assay Kit and Qubit fluorometer (Invitrogen). Afterwards, $20 \mu \mathrm{g}$ of protein from each supernatant was subjected to electrophoresis (NuPAGE 4-12\% bis-Tris gels, Invitrogen) at $165 \mathrm{~V}$ for $40 \mathrm{~min}$ and then blotted by electrotransfer onto a PVDF membrane (Invitrogen) at $30 \mathrm{~V}$ for $60 \mathrm{~min}$. The membrane was blocked in $5 \%$ non-fat dry milk in PBS with $0.1 \%$ Tween 20 (TBS) for $1 \mathrm{~h}$ at $4{ }^{\circ} \mathrm{C}$ and incubated with a mix of primary antibodies: anti-ATG5 (1:1000), anti-PER (1:10,000, kindly donated by Dr. Ralph Stanewsky, University of Münster, Germany) or antiSOD1 (1:5000, Abgent) and anti- $\alpha$ tubulin (1:20,000, Developmental Studies Hybridoma Bank) in 1\% BSA in $0.1 \%$ TBS overnight at $4{ }^{\circ} \mathrm{C}$. Next, the membrane was washed 5 times in $0.1 \%$ TBS for 10 min each time and incubated with secondary antibodies conjugated to HRP (1: 10,000, Abcam) in $0.1 \%$ TBS with $1 \%$ BSA for $1 \mathrm{~h}$ at room temperature. After incubation, the membrane was washed 5 times in $0.1 \%$ TBS and immunodetected with an ECL detection system (Perkin Elmer). Densitometric analysis of Western blot was performed using ImageJ. The experiment was repeated three times (Additional file 3: Table S3).

\section{qPCR}

Seven-day-old males $(\mathrm{N}=20)$ were decapitated at $\mathrm{ZT1}$, ZT4, ZT13 or ZT16 in LD 12:12. Heads were fixed in
$100 \%$ ethanol for $2 \mathrm{~h}$, and brains were isolated. Total RNA was isolated using TriReagent (MRC Inc.). Total RNA $(5 \mu \mathrm{g})$ was used for reverse transcription [High-Capacity cDNA Reverse Transcription Kit (ThermoFisher)] according to the manufacturer's protocol. A total of 1000 ng cDNA (diluted 1:10) was used for quantitative PCR. Each experiment was repeated three times. The expression of the following clock genes per, tim and clock was examined using TaqMan (ThermoFisher). per (Dm01843683), tim (Dm01814242) clock (Dm01795381) and reference gene rpl32 (Dm02151827) probes were also obtained from ThermoFisher. The reaction was performed using the StepOnePlus Real-Time PCR System (ThermoFisher). Data were collected as raw CT values and analysed using the $2-\Delta \Delta C T$ method. Gene expression was normalized on an arbitrary scale normalized to control (Additional file4: Table S4).

\section{Lifespan assay}

One-day-old males of each strain were placed into vials containing the standard food medium (20 flies per vial). Every 3-4 days, flies were transferred to new vials with fresh food, and the number of dead flies was counted. The experiment was repeated three times.

\section{Statistics}

The statistical analyses were performed using GraphPad Prism 6. Normal distribution of data was examined, and statistical tests were chosen accordingly. For lifespan analysis, the Kaplan-Meier test was used. The Wilcoxon-Mann-Whitney and Kruskal-Wallis tests were performed to assess differences in sleep and total activity. The results obtained from analysis of period of the circadian rhythm of locomotor activity, climbing assay, Western Blot, qPCR, ROS measurements and the fluorescent intensity associated with ATG5 level were analysed using one-way ANOVA and Tukey's test.

\section{Results}

\section{Effects of mul1 and park mutations on lifespan} and behaviour

The lifespan analysis of mul1 $^{A 6}$ and park ${ }^{1}$ mutants showed that both mutations significantly reduced longevity up to $30 \%$ and $25 \%$ in $m u l 1^{A 6}$ and park $^{1}$, respectively (Fig. 1a). mul1 ${ }^{A 6}$ and park $^{1}$ flies had longer total activity times during $24 \mathrm{~h}$ (LD 12:12) (Fig. 1b) than controls. Although the total activity was increased, the daytime sleep duration was the same across genotypes. However, the sleep duration during the night was decreased only in park $^{1}$ mutants compared to that in control. Moreover, the period of locomotor activity rhythm was lengthened to $\sim 27 \mathrm{~h}$ in park $^{1}$ mutants and $\sim 25 \mathrm{~h}$ in mul1 $^{A 6}$ mutants, 

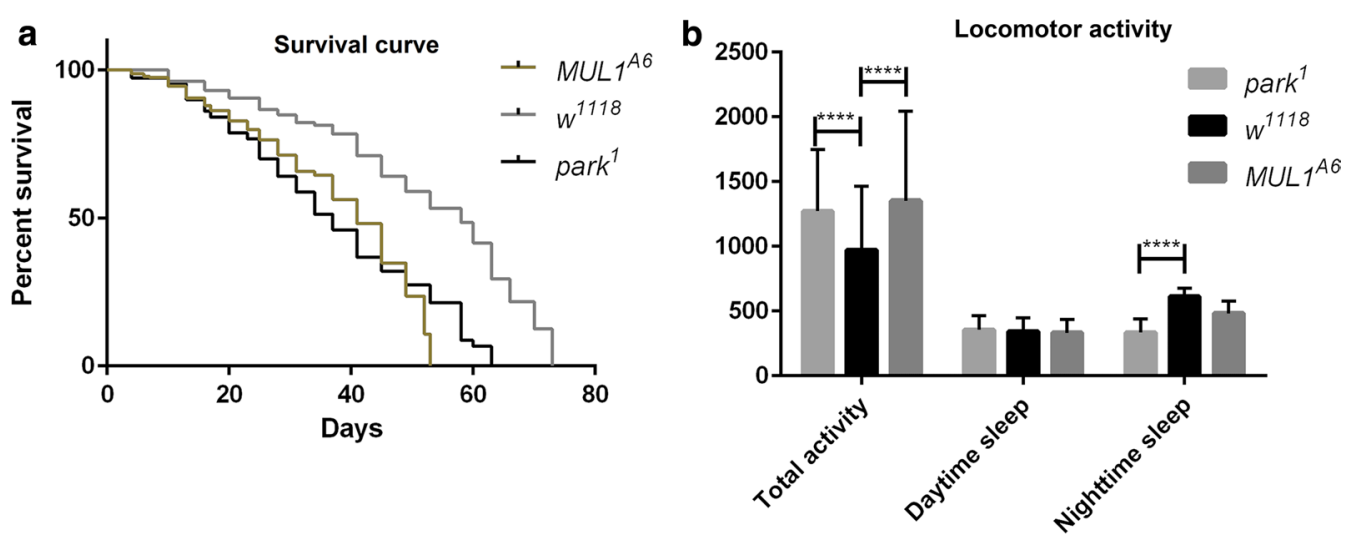

C
\begin{tabular}{|l|c|c|c|}
\hline Genotvpe & $w^{1118}$ & MUL1 $^{\text {A6 }}$ & park $^{1}$ \\
\hline Period [hl & $23.95 \pm 0.3$ & $24.58 \pm 0.5$ & $26.44 \pm 0.5$ \\
\hline
\end{tabular}

Fig. 1 Effects of mul1 and park mutations on lifespan and the circadian rhythm of locomotor activity. a Kaplan-Meier survival curve. Dead flies were counted every 3 days. Statistically significant differences were detected between white control and mul $(p<0.05)$, and also between white and park mutants $(p<0.05)$. N of $w^{1118}=231$, N of park $=150, \mathrm{~N}$ of $m u l 1^{A 6}=233$. $\mathbf{b}$ Total activity and sleep duration during the day and at night in LD 12:12. The Y-axis shows time in minutes when flies were active or their sleep time (means \pm SD) (four asterisks indicates $p<0.01$ ). $N$ of $w^{1118}=25$, $\mathrm{N}$ of park $^{\top}=29, \mathrm{~N}$ of mul $1^{A 6}=21$. c Period of locomotor activity rhythm in all studied genotypes (means $\pm \mathrm{SD}$ ). Statistically significant differences were detected between white control and mul1 $(\mathrm{p}<0.05)$, and also between white and park mutants $(\mathrm{p}<0.05)$. $\mathrm{N}$ of $w^{1118}=31, \mathrm{~N}$ of $p a r k^{1}=47, \mathrm{~N}$ of $m u l 1^{A 6}=45$

in contrast to the approximately 24-h period in white mutants, which was statistically significant (Fig. 1c).

\section{The effect of mul1 and park mutations on the circadian clock}

Examination of clock gene expression showed that mul1 and park mutations disrupted their normal expression during the day. In both mull $^{A 6}$ and park ${ }^{1}$ mutants, the morning (ZT1) peak of per expression in the brain was broader than that in the white control flies (Fig. 2a). The peak of per mRNA expression in park $^{1}$ mutants was at ZT16, while in the white control, the peak was at ZT13, and the expression of per was around $40 \%$ higher at this time point than the expression in park $^{1}$ mutants. The mul1 ${ }^{A 6}$ mutants had around $35 \%$ smaller peak in per mRNA expression at ZT13 than $w^{1118}$, but at ZT16, the per expression peak was similar to that in the control flies. Both $m u l 1^{A 6}$ and park $^{1}$ mutants had reduced mRNA levels of $t i m$ at ZT13 (70\% in park $^{1}$ and 55\% in $m u l 1^{A 6}$ ). In park $^{1}$, the maximum tim expression was at ZT16, similar to peak per expression, but in $m u l 1^{A 6}$ mutants, the level of tim mRNA was the same at ZT13 and ZT16. The morning peak was the same in all genotypes studied (Fig. 2b). Daily oscillation of $c l k$ was only changed in park $^{1}$ mutants, in which the peak at ZT13 was the same as that at ZT4, and the peak at ZT16 was five times higher than that in the white controls (Fig. 2c). Analysis of PER in the whole Drosophila brain showed that, in park $^{1}$ mutants, PER protein expression did not differ among the ZT1, ZT4 and ZT13 time points, but at ZT16, PER protein expression was lower than the expression in white controls, in which the highest PER abundance was observed at ZT16. The level of PER at ZT1, ZT4 and ZT13 was 20, 25 and $60 \%$ higher, respectively, then the level in $w^{1118}$ flies. $m u l 1^{A 6}$ mutants showed a similar level of PER at ZT1 as control flies, but at ZT4 and ZT13, the level of PER was $50 \%$ and $65 \%$ higher, respectively. PER protein expression was at its lowest at ZT16 (Fig. 2d, e).

\section{The effect of mul1 and park mutations on ROS and endogenic antioxidants}

Western blot analyses showed that the level of the main endogenous antioxidant superoxide dismutase (SOD1) was reduced in mul1 $^{A 6}$ and park $^{1}$ mutants by $55 \%$ and $45 \%$, respectively, compared with the level in the control (Fig. 3a). Moreover, measurements of the fluorescence intensity associated with the free radical level in the whole Drosophila brain showed that the total ROS level was increased by $40 \%$ in both mutants (Fig. 3b).

\section{mul1 and park mutations reduce autophagy}

Labelling of the clock neurons l-LNvs with antibodies against ATG5, an autophagy protein, and PDF, which is expressed in all 1-LNvs, showed co-localization of both proteins in cell bodies of the l-LNvs (Fig. $4 a-c)$. The analysis of fluorescence intensity associated with ATG5 

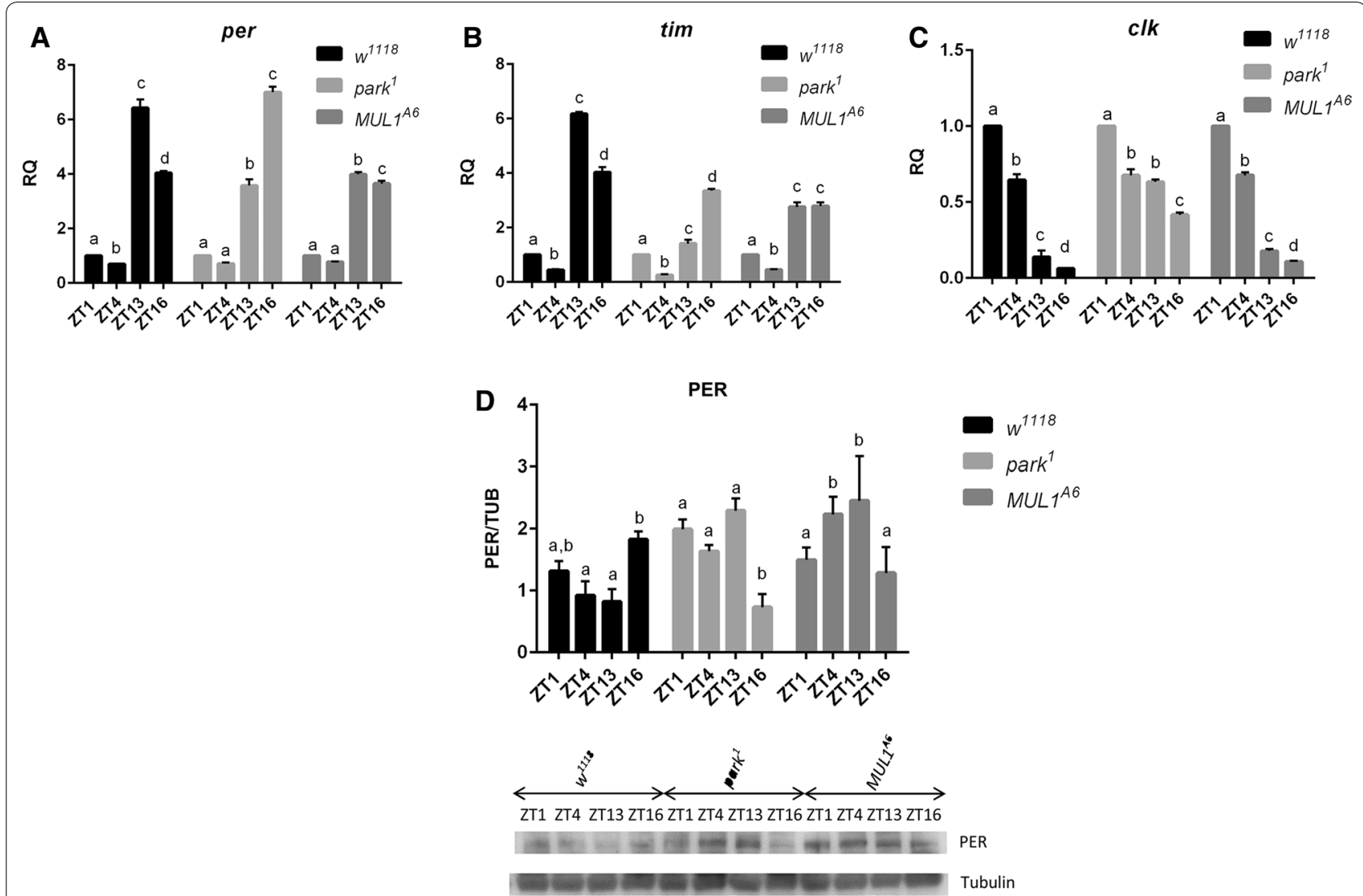

Fig. 2 Effects of mul1 and park mutations on the circadian clock. A-C Expression of selected clock genes in the Drosophila brain at four time points: ZT1, ZT4, ZT13, and ZT16 (means \pm SD). Letters a, b, c and d indicate significant differences. Statistically significant differences are between $a$ versus $b, a$ versus $c$, $a$ versus $d, b$ versus $c, b$ versus $d, c$ versus $d(p<0.01)$ in each chart. $N$ of $w^{1118}=60, N$ of $p a r k{ }^{1}=60, N$ of mul $^{A 6}=60 . N$ of $w^{1118}=60, N$ of park $^{1}=60, \mathrm{~N}$ of mul1 $^{A 6}=60$. D PER protein level in the Drosophila brain at four time points: ZT1, ZT4, ZT13, and ZT16 (means \pm SD). Letters a, b, $c$ and $d$ indicate significant differences. Statistically significant differences are between $a$ versus $b, a$ versus $c, a$ versus $d, b$ versus $c, b$ versus $d, c$ versus $d(p<0.05)$. $N$ of $w^{1118}=90, N$ of park $^{1}=90, \mathrm{~N}$ of mul $^{A 6}=90$

expression in these neurons showed that in $m u l 1^{A 6}$ mutants, ATG5 abundance was decreased when compared with that in the control, while in park $^{1}$ mutants, this difference was not statistically significant (Fig. 4d). The level of ATG5 in the whole brain in $m u l 1^{A 6}$ and park $^{1}$ mutants was decreased by $70 \%$ and $20 \%$, respectively, compared with that in the control (Fig. 4e). ATG5 showed expression almost everywhere in the brain, however, this signal was stronger in the l-LNvs and after the same settings of LSM it was possible to investigate the co-localization of ATG5 and PDF.

\section{Discussion}

MUL1 and PARKIN proteins are responsible for mitophagy and seem to be involved in the development of Parkinson's disease. Lack of these proteins leads to a reduced number of mitochondria and enlargement of their size $[6,9]$. Our results showed that mutations in mul1 and park increase ROS levels in the Drosophila brain, which origin from damaged mitochondria. While low levels of ROS are typical for normal cell metabolism, their excessive amounts cause oxidative stress and damage critical components of the cell by protein and lipid oxidation [20, 21]. Moreover, both mutations contribute to the reduction of SOD1, one of the main antioxidant proteins. SOD1 reduces free radical oxygen species, and its low level leads to the accumulation of ROS and the beginning of oxidative stress [22]. We also found changes of ATG5 level. The abundance of one of the core autophagy proteins, ATG5, was decreased in $m u l 1^{A 6}$ and park $^{1}$ mutants, which suggests that autophagy is inhibited in both mutants. The failure of autophagy machinery to efficiently remove defective proteins or damaged organelles from the cytosol, increases the level of damaged cellular components [23] which accumulate inside the cell. On the other hand, it has been shown that higher oxidative stress causes an increase of autophagy to remove damaged proteins that may be a source of 

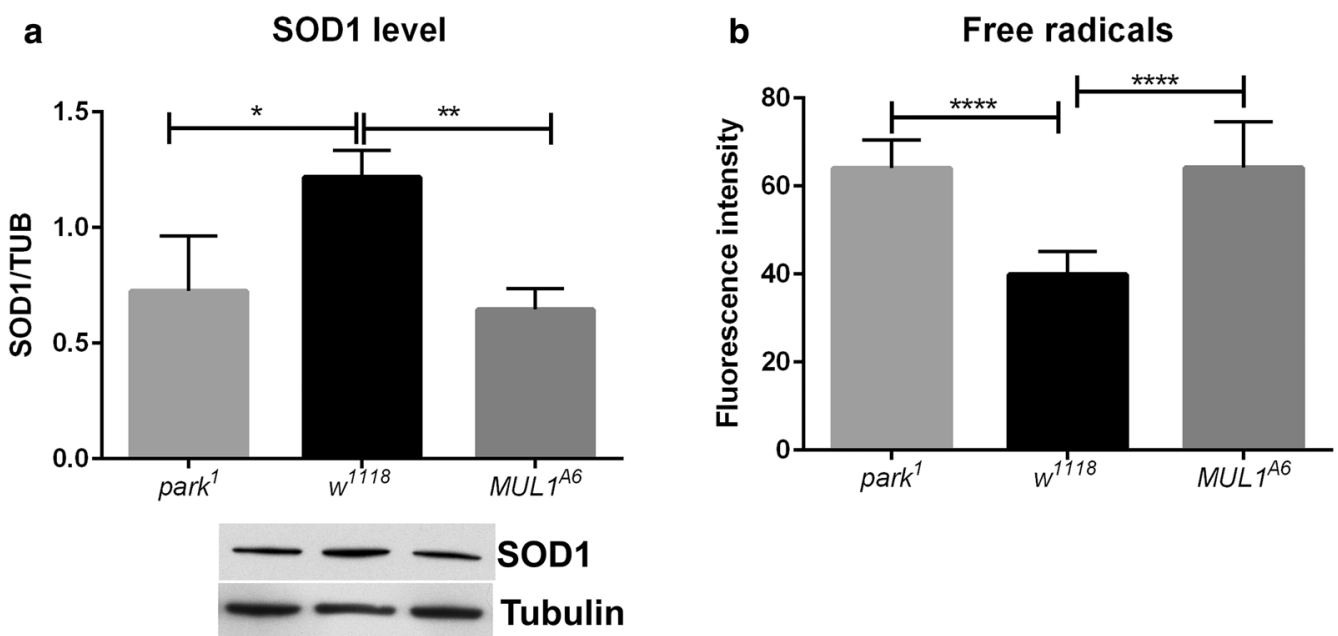

Fig. 3 Effects of mul1 and park mutations on SOD1 and ROS levels. a SOD1 level in the Drosophila brain (means \pm SD). Statistically significant differences were found between all genotypes studied (one asterisks indicates $p=0.05$; two asterisks indicate $p<0.05$ ). $N$ of $w^{1118}=90, N$ of park $^{1}=90, \mathrm{~N}$ of mul $^{A 6}=90 . \mathbf{b}$ ROS level in the Drosophila brain (four asterisks indicate $\mathrm{p}<0.01$ ) (means $\pm \mathrm{SD}$ ). $\mathrm{N}$ of $\mathrm{w}^{1118}=27, \mathrm{~N}$ of $p a r k^{1}=25, \mathrm{~N}$ of $m u l 1^{A 6}=28$

oxidative stress [24, 25]. However, when intracellular stress remains unresolved, prolonged autophagy upregulation progresses into autophagy defect [26]. This finding explains why, despite of the increased ROS level, mul1 and park mutants exhibited a decrease in the level of ATG5.

As previously mentioned, patients suffering from Parkinson's disease exhibit sleep problems and have reduced lifespan. Our findings showed that in mul1 and park models of $\mathrm{PD}$, the lifespan is strongly reduced. The short lifespan may result from the reduced ATP levels. A low level of ATP was found in mutants of the pink1 gene encoding PINK1, a kinase involved in mitophagy, which acts together with PARKIN. Moreover, mitochondrial morphology defects are similar in pink1, park ${ }^{1}$ and mul1 ${ }^{A 6}$ mutants. Therefore, the level of ATP can be concluded to be reduced with mutations of genes encoding mitochondrial ligases [27]. Furthermore, the results obtained by other authors suggest that inhibition of autophagy by reducing ATG9 (another autophagy protein) levels shortens the lifespan [28], and also ATG5 protein is responsible for. In addition to the shortened life time in mutants, we also observed increased locomotor activity and sleep disorders. The results of other authors confirm our results that the park mutation increases the daily locomotor activity of Drosophila melanogaster [29]. As mentioned previously, sleep is regulated by the circadian clock [30,31] and in Drosophila is controlled via PDF-positive l-LNv neurons. They regulate total sleep as well as the rate of sleep onset [32]. Thus, sleep disorders may not results directly due to autophagy disruption and/ or oxidative stress, but also indirectly due to circadian clock damage.

We also examined how the molecular circadian clock works in the mutant studied. The molecular mechanism of the circadian clock is based on the rhythmic expression of the core clock genes and proteins. First, we found differences in the daily expression profile of clock genes and PER protein in park $^{1}$ and mul1 $^{A 6}$ mutants. In park ${ }^{1}$ mutants, there was a shift of the peak of per and tim mRNAs to ZT16 and changes in the clock gene expression rhythm. In turn, in the mul1 ${ }^{A 6}$, mutants changes in the expression level of clock genes were observed, while the rhythms remained similar to those in the control. Despite the fact that the per gene in both mutants is rhythmically expressed, the rhythm of PER protein is completely disrupted. Between the maximum of per and tim mRNA levels and appearance of the maximum of their proteins is about $4 \mathrm{~h}$ shift (white control) due to post-transcriptional processing, translation and posttranslational processes [33]. The differences between per transcription and PER translation may originate from abnormal activity of translational factors. Increased levels of ROS have been reported to affect the activity of the eIF $2 \alpha$ translation factor [34]. In turn, the increased activity of eIF $2 \alpha$ enhances the expression of various proteins, including PER, under stress conditions. High ROS levels may also degrade SLIMB, a core protein responsible for PER degradation in proteasomes [35]. Low SLIMB activity may result in the inhibition of PER degradation, thus increasing the PER level and changing its expression profile. ROS can also "reset" the circadian clock by 


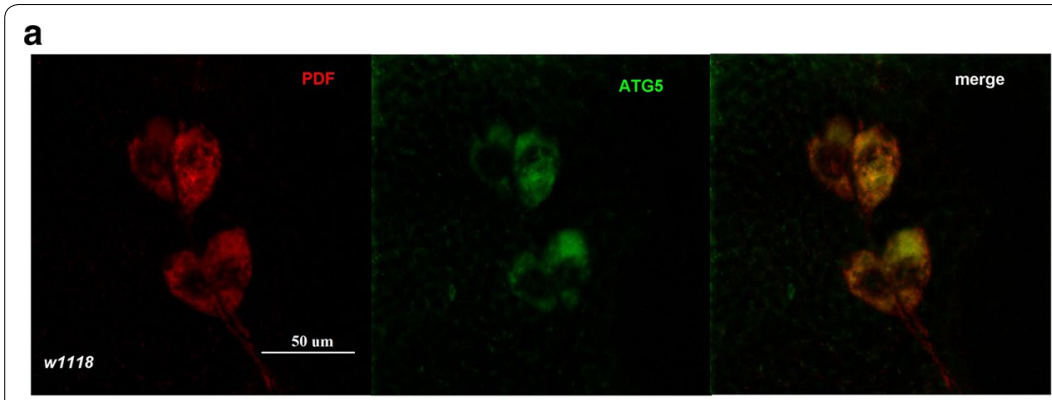

b

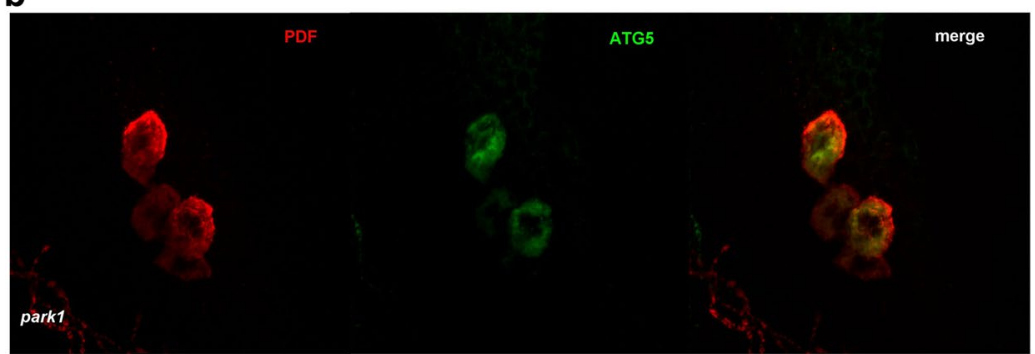

C

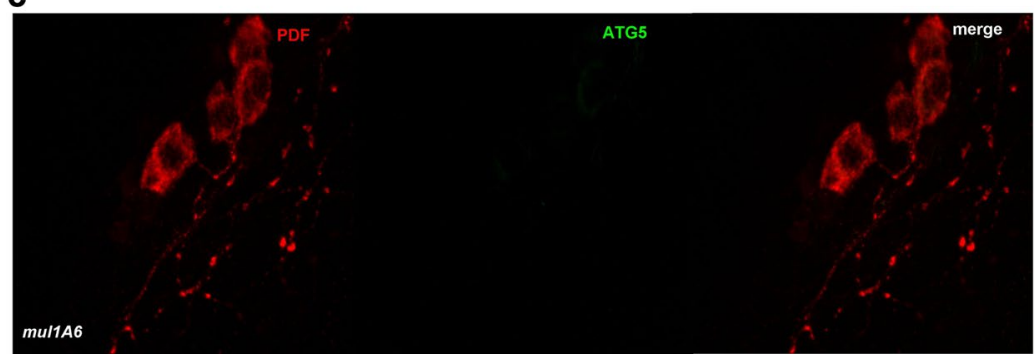

d ATG5 level in ILNvs (A-C images)

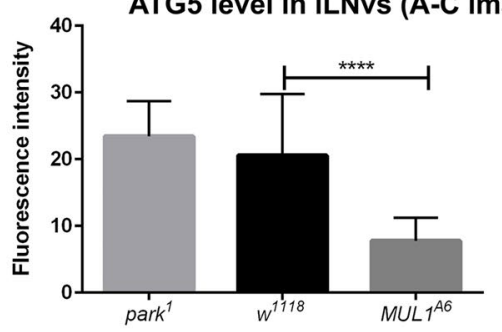

e ATG5 level in whole brain
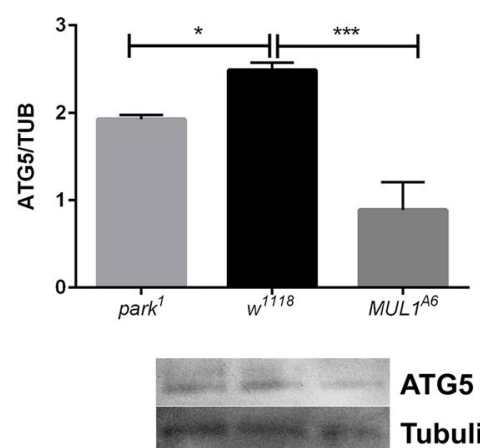

ATG5

Fig. 4 Effects of mul1 and park mutations on ATG5 expression level in clock neurons and the Drosophila brain. a-c Co-localization of ATG5 and PDF in cell bodies of large ventral lateral clock neurons in $w^{1118}(\mathbf{a})$, $\operatorname{park}^{\top}(\mathbf{b})$ and $m u l 1^{A 6}$ (c). Scale bar: $50 \mu \mathrm{m}$. d ATG5 level in the I-LNvs (four asterisks indicate $\mathrm{p}<0.01$ ) (means \pm SD). $\mathrm{N}$ of $w^{1118}=23, \mathrm{~N}$ of $\mathrm{park}^{1}=21, \mathrm{~N}$ of mul $1^{A 6}=15$. e ATG5 in the whole Drosophila brain (means \pm SD). Statistically significant differences were found between all genotypes studied (one asterisk indicates $p<0.05$; three asterisks indicate $p<0.01$ ). N of $w^{1118}=90, \mathrm{~N}$ of park $^{1}=90, \mathrm{~N}$ of mul $^{\mathrm{AC}}=90$

modifying casein kinase 2 (CK2) [36]. CK2 phosphorylates PER and TIM and changes their levels, which may result in altered post-translational modification of PER [37]. ROS may also control the expression of clock genes. In mammals, a high level of ROS results in strong induction of clock gene expression [38]. ROS can also degrade transcription factors that regulate the expression of clock genes and proteins controlling the mRNA stability of clock proteins such as double-time kinase, NEMO kinase, VRILLE and PDP1ع [39-41]. A Shift in the transcription of clock genes between mutants and control may also be disturbed by changes in the level of other clock proteins: VRILLE and PDP1 $\varepsilon$. These proteins act in the clock positive feedback loop, inhibiting and resuming the expression of the clock gene [42]. It is possible that the level and rhythmicity of these proteins is also altered, as in the case of PER protein, which in turn may cause the shift in the expression of per and tim clock genes in the mutants. However, more studies on other clock genes and proteins are needed. This shift can also be directly caused by the influence of oxidative stress and autophagy inhibition. We also found the co-localization of ATG5 and PDF in the somata of l-LNvs, which indicates that the clock proteins may also be degraded by autophagy. The l-LNvs are neurons in which the examined genes are expressed as well as PER at certain time of the day [43-45]. We observed that the level of ATG5 in these cells is reduced in both mutants, which may confirm the relationship between autophagy and the circadian clock. The difference between the results obtained in park and mul1 is most likely due to the various functions of these proteins. Although PARKIN and MUL1 proteins are mitochondrial ligases involved in mitophagy, they also participate in other physiological processes. MUL1 participates in SUMOylation, i.e., the additional post-translational processing of proteins. SUMOylation 
can stabilize some proteins, such as a glucose transporter, on the cell membrane and is therefore necessary for their proper functioning [46]. SUMOylation can also stabilize tau and alpha-synuclein proteins, and the inhibition of this process may lead to the development of Parkinson's disease [47]. SUMOylation also protects proteins against free radicals [48]. Inhibition of SUMOylation can thereby increase the sensitivity of proteins to ROS.

The main function of the circadian clock is to generate circadian rhythms in many gene expression in clock cells and transmit this information via eferential pathways to other tissues, thereby regulating the expression of genes and proteins of physiological, as well as various behavioral processes. An example of such behavioral process is the previously described sleep duration, as well as the rhythm of locomotor activity, for which per positive neurons are responsible for $[49,50]$. Our results showed that mul1 and park mutations cause the rhythm of locomotor activity period to be prolonged. In the case of park mutation, it has already been confirmed by another group of scientists who received a result similar to ours [29]. Mutations of the tested genes abolish the rhythm of the PER protein, and as a result the information about changing rhythms is erroneously transmitted to the effector tissues and disorders in the circadian rhythm of locomotor activity arise. This result is similar to the case in which per is mutated in many different forms $[49,50]$, which makes it even more convinced that mul1 and park mutations lead to the circadian clock disruption.

\section{Conclusions}

In conclusion, in the present study, we found that mul1 and park mutations, which are involved in the development of Parkinson's disease, disturb several processes in an organism, including circadian rhythms in behaviour and the molecular mechanism of the clock. This effect seems to originate from increased levels of free radicals and the inhibition of autophagy, which is important in circadian rhythm generation [51].

\section{Additional files}

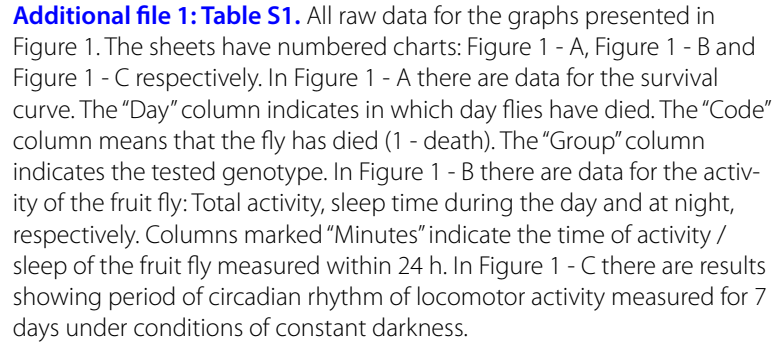

Additional file 2: Table S2. All raw data for the graphs presented in Figure 1. The sheets have numbered charts: Figure 2 - A, Figure 2 - B, Figure 2 - $C$ and Figure $2-D$ respectively. In Figure 2-A / B / C, there are presented results $(\mathrm{RQ})$ for the expression of the per, tim and clock genes, respectively, at four time points. All data was averaged to the rp/32. Figures 2 - C show data for Western Blot analysis of PER protein. Data comes from densitometry, and has been averaged to load control - alpha tubulin

Additional file 3: Table S3. All raw data for the graphs presented in Figure 1. The sheets have numbered charts: Figure 3 - A and Figure 3 - B, respectively. Figure 3 - A shows the data for Western Blot analysis of the SOD1 protein. Results from densitometry have been averaged to load control - alpha tubulin. In Figure 3 - B there are data (fluorescence intensity measured using the ImageJ) showing the level of free radicals.

Additional file 4: Table S4. All raw data for the graphs presented in Figure 1. The sheets have numbered charts: Figure $4-D$ and Figure $4-E$ respectively. Figure 4 - $D$ shows the results (fluorescence intensity measured using the ImageJ) level of ATG5 protein in PDF-positive perycaryon of I-LNvs. In Figure 4 - E, the results of Western blot analysis of the ATG5 protein in the canine fruit fly are shown. Densitometry results were averaged to load control - alpha tubulin.

\section{Abbreviations}

PD: Parkinson's disease; I-LNvs: large lateral neurons ventral; s-LNvs: small lateral neurons ventral; LNds: lateral neurons dorsal; DN: dorsal neurons; LPNs: lateral posterior neurons; PER: period; TIM: timeless; CLK: clock; CYC: cycle; DD: constant darkness; LD: light:dark.

\section{Acknowledgements}

In this study we used a Zeiss LSM 510 confocal microscope in the Laboratory of Microscopy, Department of Cell Biology and Imaging, Institute of Zoology and Biomedical Research, Jagiellonian University.

\section{Authors' contributions}

$\mathrm{BD}$ was conducting experiments and writing a first draft of the paper. MD helped in planning experiments and writing the paper. EP was involved in planning experiments, analyzing the results, writing the paper and she provided the funding. All authors read and approved the final manuscript.

\section{Funding}

Supported from DSC 2017 Grant to BD and K/ZDS/007356, K/ZDS/008070

Grants of the Jagiellonian University.

\section{Availability of data and materials}

The datasets obtained and analysed during the current study are available from the first and corresponding Authors on request.

Ethics approval and consent to participate

Not applicable.

Consent for publication

Not applicable.

Competing interests

The authors declare that they have no competing interests.

Received: 4 March 2019 Accepted: 15 May 2019

Published online: 28 May 2019

References

1. Trevisan T, Pendin D, Montagna A, Bova S, Ghelli AM, Daga A. Manipulation of mitochondria dynamics reveals separate roles for form and function in mitochondria distribution. Cell Rep. 2018;23:1742-53. https://doi. org/10.1016/j.celrep.2018.04.017.

2. Zilocchi M, Finzi G, Lualdi M, Sessa F, Fasano M, Alberio T. Mitochondrial alterations in Parkinson's disease human samples and cellular models. 
Neurochem Int. 2018;118:61-72. https://doi.org/10.1016/j.neuin t.2018.04.013.

3. Kitada T, Asakawa S, Hattori N, Matsumine H, Yamamura Y, Minoshima S, et al. Mutations in the parkin gene cause autosomal recessive juvenile parkinsonism. Nature. 1998;392:605-8. https://doi.org/10.1038/33416.

4. Valente EM, Abou-Sleiman PM, Caputo V, Muqit MMK, Harvey K, Gispert $S$, et al. Hereditary early-onset Parkinson's disease caused by mutations in PINK1. Science. 2004;304(80):1158-60. https://doi.org/10.1126/scien ce.1096284.

5. Clark IE, Dodson MW, Jiang C, Cao JH, Huh JR, Seol JH, et al. Drosophila pink1 is required for mitochondrial function and interacts genetically with parkin. Nature. 2006;441:1162-6. https://doi.org/10.1038/nature0477 9.

6. Park J, Lee SB, Lee SB, Kim Y, Song S, Kim S, et al. Mitochondrial dysfunction in Drosophila PINK1 mutants is complemented by parkin. Nature. 2006:441:1157-61. https://doi.org/10.1038/nature04788.

7. Matsuda N, Sato S, Shiba K, Okatsu K, Saisho K, Gautier CA, et al. PINK1 stabilized by mitochondrial depolarization recruits Parkin to damaged mitochondria and activates latent Parkin for mitophagy. J Cell Biol. 2010;189:211-21.

8. Narendra D, Tanaka A, Suen D-F, Youle RJ. Parkin is recruited selectively to impaired mitochondria and promotes their autophagy. J Cell Biol. 2008;183:795-803. https://doi.org/10.1083/jcb.200809125.

9. Yun J, Puri R, Yang H, Lizzio MA, Wu C. MUL1 acts in parallel to the PINK1/ parkin pathway in regulating mitofusin and compensates for loss of PINK1/parkin. 2014. P. 1-26.

10. Suzuki K, Okuma Y, Uchiyama T, Miyamoto M, Sakakibara R, Shimo Y, et al. Impact of sleep-related symptoms on clinical motor subtypes and disability in Parkinson's disease: a multicentre cross-sectional study. J Neurol Neurosurg Psychiatry. 2017;88:953-9. https://doi.org/10.1136/jnnp-2017316136.

11. Ahsan Ejaz A, Sekhon IS, Munjal S. Characteristic findings on 24-h ambulatory blood pressure monitoring in a series of patients with Parkinson's disease. Eur J Intern Med. 2006;17:417-20. https://doi.org/10.1016/j. ejim.2006.02.020.

12. Mistlberger RE. Circadian regulation of sleep in mammals: Role of the suprachiasmatic nucleus. Brain Res Rev. 2005;49:429-54. https://doi. org/10.1016/j.brainresrev.2005.01.005.

13. Tong J, Qin $L Q$, Wang DJ. Mechanism of pineal and suprachiasmatic regulation on circadian rhythm of body temperature in rats. Space Med Med Eng (Beijing). 2000;13:101-3. http://www.ncbi.nlm.nih.gov/pubme d/11543047. Accessed 15 May 2018.

14. Helfrich-Förster $C$. The circadian clock in the brain: a structural and functional comparison between mammals and insects. J Comp Physiol A. 2004;190:601-13. https://doi.org/10.1007/s00359-004-0527-2.

15. Peschel N, Helfrich-Förster C. Setting the clock-by nature: Circadian rhythm in the fruitfly Drosophila melanogaster. FEBS Lett. 2011;585:143542. https://doi.org/10.1016/j.febslet.2011.02.028.

16. Cha G-H, Kim S, Park J, Lee E, Kim M, Lee SB, et al. Parkin negatively regulates JNK pathway in the dopaminergic neurons of Drosophila. Proc Natl Acad Sci USA. 2005;102:10345-50. https://doi.org/10.1073/pnas.05003 46102.

17. Krstic D, Boll W, Noll M. Influence of the White locus on the courtship behavior of Drosophila males. PLoS ONE. 2013;8:e77904. https://doi. org/10.1371/journal.pone.0077904.

18. Rosato E, Kyriacou CP. Analysis of locomotor activity rhythms in Drosophila. Nat Protoc. 2006;1:559-68. https://doi.org/10.1038/nprot.2006.79.

19. Scialò F, Sriram A, Fernández-Ayala D, Gubina N, Lõhmus M, Nelson G, et al. Mitochondrial ROS produced via reverse electron transport extend animal lifespan. Cell Metab. 2016;23:725-34. https://doi.org/10.1016/j. cmet.2016.03.009.

20. Aitken RJ, Clarkson JS, Fishel S. Generation of reactive oxygen species, lipid peroxidation, and human sperm function. Biol Reprod. 1989;41:18397. http://www.ncbi.nlm.nih.gov/pubmed/2553141. Accessed 19 Sep 2018.

21. Dean RT, Fu S, Stocker R, Davies MJ. Biochemistry and pathology of radical-mediated protein oxidation. Biochem J. 1997;324 (Pt 1):1-18 http://www.ncbi.nlm.nih.gov/pubmed/9164834. Accessed 19 Sept 2018.

22. Bunton-Stasyshyn RKA, Saccon RA, Fratta P, Fisher EMC. SOD1 function and its implications for amyotrophic lateral sclerosis pathology. Neuroscience. 2015;21:519-29. https://doi.org/10.1177/1073858414561795.
23. Henchcliffe C, Beal MF. Mitochondrial biology and oxidative stress in Parkinson disease pathogenesis. Nat Clin Pract Neurol. 2008;4:600-9. https:// doi.org/10.1038/ncpneuro0924.

24. Matus S, Lisbona F, Torres M, León C, Thielen P, Hetz C. The stress rheostat: an interplay between the unfolded protein response (UPR) and autophagy in neurodegeneration. Curr Mol Med. 2008;8:157-72. http:// www.ncbi.nlm.nih.gov/pubmed/18473817. Accessed 19 Sept 2018.

25. Li D-Y, Yu J-C, Xiao L, Miao W, Ji K, Wang S-C, et al. Autophagy attenuates the oxidative stress-induced apoptosis of Mc3T3-E1 osteoblasts. Eur Rev Med Pharmacol Sci. 2017;21:5548-56. http://www.ncbi.nlm.nih.gov/ pubmed/29271985. Accessed 15 May 2018.

26. Cai D, Liu T. Inflammatory cause of metabolic syndrome via brain stress and NF-KB. Aging (Albany NY). 2012;4:98-115. https://doi.org/10.18632/ aging. 100431.

27. Yang Y, Gehrke S, Imai Y, Huang Z, Ouyang Y, Wang J-W, et al. Mitochondrial pathology and muscle and dopaminergic neuron degeneration caused by inactivation of Drosophila Pink1 is rescued by Parkin. Proc Natl Acad Sci USA. 2006;103:10793-8.

28. Wen J-K, Wang Y-T, Chan C-C, Hsieh C-W, Liao H-M, Hung C-C, et al. Atg9 antagonizes TOR signaling to regulate intestinal cell growth and epithelial homeostasis in Drosophila. Elife. 2017. https://doi.org/10.7554/elife.29338

29. Julienne H, Buhl E, Leslie DS, Hodge JJL. Drosophila PINK1 and parkin loss-of-function mutants display a range of non-motor Parkinson's disease phenotypes. Neurobiol Dis. 2017;104:15-23. https://doi. org/10.1016/j.nbd.2017.04.014.

30. Cavanaugh DJ, Vigderman AS, Dean T, Garbe DS, Sehgal A. The Drosophila circadian clock gates sleep through time-of-day dependent modulation of sleep-promoting neurons. Sleep. 2016;39:345-56. https:// doi.org/10.5665/sleep.5442.

31. Zhou L, Bryant CD, Loudon A, Palmer AA, Vitaterna MH, Turek FW. The circadian clock gene Csnk1e regulates rapid eye movement sleep amount, and nonrapid eye movement sleep architecture in mice. Sleep. 2014;37:785-93. https://doi.org/10.5665/sleep.3590.

32. Parisky KM, Agosto J, Pulver SR, Shang Y, Kuklin E, Hodge JJL, et al. PDF cells are a GABA-responsive wake-promoting component of the Drosophila sleep circuit. Neuron. 2008;60:672-82. https://doi.org/10.1016/J. NEURON.2008.10.042.

33. Hardin PE, Hall JC, Rosbash M. Feedback of the Drosophila period gene product on circadian cycling of its messenger RNA levels. Nature. 1990;343:536-40. https://doi.org/10.1038/343536a0.

34. Lee IC, Ho XY, George SE, Goh CW, Sundaram JR, Pang KKL, et al. Oxidative stress promotes SIRT1 recruitment to the GADD34/PP1 a complex to activate its deacetylase function. Cell Death Differ. 2018;25:255-67. https ://doi.org/10.1038/cdd.2017.152.

35. Grima B, Lamouroux A, Chélot E, Papin C, Limbourg-Bouchon B, Rouyer F. The F-box protein Slimb controls the levels of clock proteins period and timeless. Nature. 2002;420:178-82. https://doi.org/10.1038/nature01122.

36. Tamaru T, Hattori M, Ninomiya Y, Kawamura G, Varès G, Honda K, et al. ROS stress resets circadian clocks to coordinate pro-survival signals. PLOS ONE. 2013;8:e82006. https://doi.org/10.1371/journal.pone.0082006.

37. Lin J-M, Kilman VL, Keegan K, Paddock B, Emery-Le M, Rosbash M, et al. A role for casein kinase $2 a$ in the Drosophila circadian clock. Nature. 2002;420:816-20. https://doi.org/10.1038/nature01235.

38. Tahara Y, Shibata S. Entrainment of the mouse circadian clock: effects of stress, exercise, and nutrition. Free Radic Biol Med. 2018;119:129-38. https ://doi.org/10.1016/j.freeradbiomed.2017.12.026.

39. Akten B, Jauch E, Genova GK, Kim EY, Edery I, Raabe T, et al. A role for CK2 in the Drosophila circadian oscillator. Nat Neurosci. 2003;6:251-7. https:// doi.org/10.1038/nn1007.

40. Cyran SA, Buchsbaum AM, Reddy KL, Lin M-C, Glossop NRJ, Hardin PE, et al. vrille, Pdp1, and dClock form a second feedback loop in the Drosophila circadian clock. Cell. 2003;112:329-41. http://www.ncbi.nlm.nih. gov/pubmed/12581523. Accessed 15 May 2018.

41. Kloss B, Price JL, Saez L, Blau J, Rothenfluh A, Wesley CS, et al. The Drosophila clock gene double-time encodes a protein closely related to human casein kinase lepsilon. Cell. 1998;94:97-107. http://www.ncbi.nIm. nih.gov/pubmed/9674431. Accessed 15 May 2018.

42. Blau J, Young MW. Cycling vrille expression is required for a functional Drosophila clock. Cell. 1999;99:661-71. https://doi.org/10.1016/S0092 $-8674(00) 81554-8$. 
43. Myers MP, Wager-Smith K, Rothenfluh-Hilfiker A, Young MW. Lightinduced degradation of TIMELESS and entrainment of the Drosophila circadian clock. Science. 1996;271:1736-40. http://www.ncbi.nlm.nih. gov/pubmed/8596937. Accessed 20 Sep 2018.

44. Siwicki KK, Eastman C, Petersen G, Rosbash M, Hall JC. Antibodies to the period gene product of Drosophila reveal diverse tissue distribution and rhythmic changes in the visual system. Neuron. 1988;1:141-50. http:// www.ncbi.nlm.nih.gov/pubmed/3152288. Accessed 20 Sep 2018.

45. Zerr DM, Hall JC, Rosbash M, Siwicki KK. Circadian fluctuations of period protein immunoreactivity in the CNS and the visual system of Drosophila. J Neurosci. 1990;10:2749-62. http://www.ncbi.nlm.nih.gov/pubme d/2117644. Accessed 20 Sep 2018.

46. Giorgino F, de Robertis O, Laviola L, Montrone C, Perrini S, McCowen KC et al. The sentrin-conjugating enzyme mUbc9 interacts with GLUT4 and GLUT1 glucose transporters and regulates transporter levels in skeletal muscle cells. Proc Natl Acad Sci USA. 2000;97:1125-30. http://www.ncbi. nlm.nih.gov/pubmed/10655495. Accessed 15 May 2018.

47. Dorval V, Fraser PE. Small ubiquitin-like modifier (SUMO) modification of natively unfolded proteins Tau and a-synuclein. J Biol Chem. 2006;281:9919-24. https://doi.org/10.1074/jbc.M510127200.
48. Marcelli S, Ficulle E, Piccolo L, Corbo M, Feligioni M. An overview of the possible therapeutic role of SUMOylation in the treatment of Alzheimer's disease. Pharmacol Res. 2018;130:420-37. https://doi.org/10.1016/j. phrs.2017.12.023.

49. Huang ZJ, Curtin KD, Rosbash M. PER protein interactions and temperature compensation of a circadian clock in Drosophila. Science. 1995;267:1169-72. http://www.ncbi.nlm.nih.gov/pubmed/7855598. Accessed 20 Sept 2018.

50. Loros JJ, Denome SA, Dunlap JC. Molecular cloning of genes under control of the circadian clock in Neurospora. Science. 1989;243:385-8. http:// www.ncbi.nlm.nih.gov/pubmed/2563175. Accessed 20 Sept 2018.

51. Kijak E, Pyza E. TOR signaling pathway and autophagy are involved in the regulation of circadian rhythms in behavior and plasticity of L2 interneurons in the brain of Drosophila melanogaster. PLOS ONE. 2017;12:e0171848. https://doi.org/10.1371/journal.pone.0171848.

\section{Publisher's Note}

Springer Nature remains neutral with regard to jurisdictional claims in published maps and institutional affiliations.
Ready to submit your research? Choose BMC and benefit from:

- fast, convenient online submission

- thorough peer review by experienced researchers in your field

- rapid publication on acceptance

- support for research data, including large and complex data types

- gold Open Access which fosters wider collaboration and increased citations

- maximum visibility for your research: over $100 \mathrm{M}$ website views per year

At BMC, research is always in progress.

Learn more biomedcentral.com/submissions 